\title{
Percepção de Justiça por parte do Principal e do Agente em Relação ao Princípio da Controlabilidade
}

\author{
Maria Elena Amaral Ferreira Bueno* \\ Rodrigo Angonese ${ }^{* * *}$
}

\begin{abstract}
Resumo
Este estudo objetiva verificar se a aplicação do princípio da controlabilidade influencia a percepção de justiça, tanto por parte do principal como por parte do agente. A pesquisa apresenta natureza descritiva, com abordagem quantitativa. É de caráter experimental pelo procedimento da pesquisa. A coleta de dados foi realizada por meio da aplicação de questionário para 40 alunos concluintes do curso superior de administração, representando o agente e 50 alunos de pós-graduação representando o principal. Os dados coletados foram tabulados em planilha eletrônica e submetidos a tratamento estatístico descritivo, análise de frequência e análise de correlação de Spearman. Os resultados mostram que a neutralização da interferência de gestores de mesmo nível hierárquico aumenta a percepção de justiça distributiva por parte do agente. Na concepção do principal, há correlação positiva entre a justiça distributiva e o desejo de neutralização de decisões tomadas por gestores de mesmo nível hierárquico e fatores externos, demonstrando que o principal não tem diminuída sua percepção de justiça distributiva pela aplicação do princípio da controlabilidade nestes dois quesitos, contrariando a ideia inicial que envolvia os pressupostos da Teoria da Agência.
\end{abstract}

Palavras-chave: Justiça Organizacional. Teoria da Agência. Controle de gestão. Avaliação de desempenho.

* Contadora, Mestre em Administração pelo Programa de Pós-graduação em Administração/Mestrado da Universidade de Passo Fundo -UPF, Professora da Faculdade de Ciências Econômicas Administrativas e Contábeis da Universidade de Passo Fundo - UPF. E-mail: abueno@upf.br

** Contador, Mestre em Controladoria e Contabilidade - UNISINOS, Doutor em Ciências Contábeis e Administração - FURB, Professor do Programa de Pós-graduação em Administração/Mestrado da Universidade de Passo Fundo -UPF, Professor da Faculdade de Ciências Econômicas Administrativas e Contábeis da Universidade de Passo Fundo - UPF. E-mail: rangonese@upf.br 


\section{Introdução}

Este estudo relaciona o princípio da controlabilidade e a percepção de justiça sob a ótica da teoria econômica, buscando investigar se o agente (gestores) e o principal (proprietários/acionistas) pensam de forma semelhante quanto à neutralização dos fatores internos e externos que podem influenciar o desempenho da organização e, consequentemente, o desempenho dos gestores.

Estudos na área contábil como os de Antle e Demski (1988), Aguiar et al. (2012), Angonese e Beuren (2014), Beuren, Amaro e Silva (2015), Burket, Fischer e Schaffer (2011), Giraud, Langevin e Mendoza (2008), Langevin e Mendoza (2013), Sotomayor (2007), Merchant e Van der Stede (2007) têm enfatizado o papel do princípio da controlabilidade no desenvolvimento dos sistemas de controle gerenciais e nos sistemas de avaliação de desempenho, principalmente no que se refere ao grau de controle que os gestores têm sobre as ações pelas quais eles são avaliados e a percepção de justiça decorrente da aplicação deste princípio. Segundo o princípio da controlabilidade, os gestores deveriam ser responsabilizados, avaliados e remunerados apenas pelos resultados financeiros decorrentes das atividades que possam influenciar ou controlar (Antle \& Demski, 1988).

Sotomayor (2007) evidenciou em seu estudo a importância assumida pelas percepções de justiça num contexto de avaliação de desempenho, salientando que devem ser percepcionadas como justas pelos agentes intervenientes no processo, qualquer que seja a vertente de justiça considerada (distributiva, procedimental, interpessoal ou informacional). De acordo com Langevin e Mendoza (2013) eliminar os fatores incontroláveis na avaliação de desempenho possibilita diminuir o sentimento de injustiça percebida pelos gestores, além de estar diretamente ligado ao aumento do nível de comprometimento organizacional. $\mathrm{O}$ atendimento ao princípio da controlabilidade busca evitar que gestores assumam o risco de fatores incontroláveis tais como interferências motivadas por atitudes de superiores hierárquicos, de gestores de mesmo nível hierárquico ou fatores externos como catástrofes, crises financeiras, greves, o que pode afetar negativamente o seu nível de motivação e remuneração (Langevin \& Mendoza, 2013).

Considerando a abordagem teórica do assunto, segundo Giraud et al. (2008), Beuren et al. (2015), Angonese e Beuren (2014) há um posicionamento de que nem sempre é o desejo dos gestores terem os efeitos de fatores incontroláveis anulados. O estudo de Giraud et al. (2008) demonstrou que os gestores tem interesse em ver 
neutralizadas as interferências dos fatores internos, porém, em relação aos fatores externos os gestores entendem que estas interferências fazem parte do negócio e que eles devem gerenciar e suportar este risco.

Com base nos resultados das pesquisas de Giraud et al. (2008), Burket et al. (2011), Beuren et al. (2015) este estudo pretende investigar o interesse na aplicação do princípio da controlabilidade não apenas por parte dos gestores, mas também por parte do principal, levando em consideração a percepção de justiça distributiva em relação a esta dimensão do sistema de controle gerencial. Distingue-se dos estudos já desenvolvidos por considerar a opinião de ambas as partes envolvidas neste contrato, principal e agente. Sob a ótica do agente, parece justo não ser penalizado financeiramente por acontecimentos que não pode controlar. Porém, o principal pode não interessar-se pela neutralização destes fatores, uma vez que a organização pode não ter auferido resultado suficiente para viabilizar a distribuição de recompensas aos agentes.

Diante do contexto apresentado, a questão de pesquisa que norteia este estudo é: Qual a percepção de justiça em relação a aplicação do princípio da controlabilidade por parte do principal e do agente? Assim, o objetivo do presente estudo é verificar se a aplicação do princípio da controlabilidade influencia a percepção de justiça, tanto por parte do principal como por parte do agente. Langevin e Mendoza (2013) constataram em seu estudo que a justiça percebida pela aplicação do princípio da controlabilidade afeta a relação entre o empregado e a organização como um todo (comprometimento organizacional) e influencia as relações com seus superiores, sendo que ambos levam à maior conformidade entre os objetivos organizacionais e pessoais e, dessa forma, diminuem possíveis reações em relação à injustiça percebida.

Este estudo justifica-se no sentido da contribuição teórica, por colaborar com evidências adicionais para o campo de pesquisa em administração e ciências contábeis, principalmente pela abordagem de um aspecto específico da justiça organizacional, a justiça distributiva e sua relação com uma das dimensões dos sistemas de controle gerencial, a controlabilidade, além de investigar a percepção de ambos os envolvidos na relação organizacional, principal e agente. No âmbito prático, busca contribuir para um melhor entendimento sobre o processo de avaliação de desempenho, a fim de que seja percepcionado como justo tanto pelo agente como pelo principal, pois conforme Beuren et al. (2016), questões de ordem subjetiva, como as que estão envolvidas nos julgamentos de justiça, tem grande importância no estudo das relações entre trabalhadores e suas organizações. 


\section{Fundamentação teórica}

\section{Princípio da Controlabilidade}

Para Antle e Demski (1988), entende-se por controlabilidade a avaliação de um gerente com base no que ele controla. Giraud et al. (2008), citam que o princípio da controlabilidade preconiza que os gestores devem ser avaliados com base apenas nos elementos que eles possam controlar.

Como consequência da aplicação desse princípio, os gestores deveriam ser avaliados e remunerados somente com base nas medidas de desempenho as quais eles também possam influenciar ou controlar (Antle \& Demski, 1988). Merchant e Van der Stede (2007) citam que uma das condições para que o controle financeiro possa ser efetivo é que os gestores, cujos comportamentos estão sendo avaliados, sejam capazes de influenciar, de maneira significativa, os resultados almejados.

O princípio da controlabilidade, de acordo com Giraud et al. (2008) é um dos fatores que deve ser levado em consideração no estabelecimento de sistemas de controle nas organizações, pois implica "neutralizar" fatores incontroláveis na avaliação do desempenho dos gestores, constituindo-se em um pré-requisito para o estabelecimento de um senso de justiça referente ao sistema de avaliação de desempenho. Os fatores incontroláveis envolvem três dimensões, envolvendo a neutralização das interferências causadas por: a) gestores de mesmo nível hierárquico; b) gestores de níveis hierárquicos superiores; e, c) fatores externos.

O processo de neutralização, para Merchant e Van der Stede (2007) pode assumir duas formas: neutralização ex ante, consistindo em selecionar medidas de desempenho que excluam itens que os gestores não podem controlar, e a neutralização ex post, consistindo em fazer ajustamentos de fim de ano para eliminar o impacto destes fatores no desempenho dos gestores.

\section{Justiça Organizacional}

Para Assmar, Ferreira e Souto (2005) justiça organizacional é a psicologia da justiça aplicada aos ambientes organizacionais, onde o foco são as percepções de justiça existentes nas relações entre trabalhadores e suas organizações. A justiça organizacional é a justiça percebida nas trocas que ocorrem dentro da organização, 
sejam elas econômicas ou sociais. Envolve o indivíduo e suas relações com os superiores, subordinados, pares e a organização como um todo (Beugré \& Baron, 2001).

A justiça organizacional envolve um conjunto de dimensões, a justiça distributiva ligada à distribuição dos resultados (outcomes); a justiça procedimental ou processual, diz respeito aos procedimentos utilizados para determinar essa distribuição; e a justiça interacional, relacionada à qualidade do tratamento interpessoal, sendo que esta última pode ser dividida em justiça informativa e justiça interpessoal (Sotomayor, 2007; Langevin \& Mendoza, 2013).

Assmar et al. (2005) citam que outras duas dimensões são também propostas, ainda que pouco estudadas: a justiça sistêmica, que se vincula à justiça da organização como um sistema social e a justiça retributiva, cuja preocupação central é estudar como as pessoas reagem à violação de normas sociais e como se processam os julgamentos sobre responsabilidade e aplicação de sansões. Segundo Beugré \& Baron (2001), a literatura sobre justiça organizacional oferece poucas informações sobre como os empregados estabelecem senso de justiça sobre a organização como um todo, ou seja, a justiça sistêmica.

A primeira dimensão de justiça organizacional foi a justiça distributiva, desenvolvida por Adams, em sua teoria da equidade (Sotomayor, 2007 p.89), sendo que esta dimensão analisa as percepções de justiça dos empregados referente aos resultados que eles recebem da organização, como: classificações de desempenho, promoções, aumentos salariais, prêmios de fim de ano e participação em programas de formação, em contrapartida as entradas que fornecem à organização, como inteligência, formação, aptidões, experiência e esforço despendido na execução das suas tarefas. A justiça distributiva torna-se um dos principais orientadores no ambiente organizacional, sendo que muitas vezes a comparação com o outro é feita sob influência de que, o que é justo é proporcional, ou seja, a expectativa é que o resultado seja igual entre os pares (Folger \& Cropanzano, 1998). Normalmente, a regra utilizada para estabelecer as comparações entre indivíduos é a regra da equidade, ou seja, reconhecer imparcialmente o direito de cada um (Folger \& Cropanzano, 1998; Sotomayor, 2006).

Beuren et al. (2016), Sotomayor (2006), citam que pesquisas relativas à justiça organizacional têm revelado as diferentes formas de reações às injustiças percebidas, bem como comportamentos decorrentes deste sentimento tais como stress, absenteísmo, rotatividade, falta de comprometimento, entre outros. Diante do exposto, percebe-se que o alcance da justiça nas organizações é tarefa complexa, pois 
segundo Beuren et al. (2015) envolve um conjunto de fatores internos e externos, que estão ligados ao processo de avaliação de desempenho e às regras de distribuição de benefícios entre os empregados.

Este estudo prioriza o enfoque da justiça distributiva, que diz respeito a como uma organização distribui os recursos financeiros disponíveis entre seus empregados. Faz referência a aspectos ligados ao retorno financeiro que os gestores esperam receber em virtude do esforço despendido por eles no exercício de suas atividades. Desta forma, a aplicação do princípio da controlabilidade pressupõe-se pré-requisito para o estabelecimento de um senso de justiça na avaliação de desempenho dos gestores (Langevin \& Mendoza, 2013).

\section{Desenvolvimento das hipóteses}

O princípio da controlabilidade é fundamental na elaboração de um sistema de controle gerencial para fins de avaliação de desempenho dos gestores, pois segundo Langevin e Mendoza (2013), a remoção de fatores incontroláveis das avaliações dos gestores aumenta a convicção de que a avaliação do desempenho será inerente aos esforços e não aos acontecimentos imprevisíveis. Merchant e Van der Stede (2007) ressaltam que é supostamente mais ético não penalizar os gestores quando seus resultados são afetados negativamente por eventos incontroláveis.

Giraud et al. (2008) citam que a aplicação do princípio da controlabilidade aparenta ser do interesse da organização e também dos gestores avaliados, pois a desmotivação dos gestores pode resultar em comportamento gerencial prejudicial. Desta forma e, embasado no estudo de Langevin e Mendoza (2013) quando o princípio da controlabilidade não é aplicado, e se eventos incontroláveis afetarem negativamente os resultados, existe o risco de haver um sentimento por parte do agente de que os benefícios concedidos não foram justos, por não compensarem o esforço despendido. Neste sentido, sua aplicação é uma tentativa de protegê-los da incerteza, bem como aumentar a sua percepção de justiça distributiva na relação entre esforço e recompensa. Diante do exposto, presume-se que a aplicação do princípio da controlabilidade influencia positivamente a percepção de justiça distributiva por parte do agente, portanto, enuncia-se a seguinte hipótese:

$\mathbf{H}_{1}$ : Na concepção do agente (representado pelos alunos concluintes do curso de administração), a aplicação do princípio da controlabilidade aumenta a percepção de justiça distributiva em relação ao Sistema de Controle Gerencial.

Teoria e Evidência Econômica - a. 27, n. 56, p. 33-53, jan./jun. 2021 
Além da perspectiva do agente em relação à neutralização das interferências causadas por gestores de mesmo nível hierárquico, gestores de níveis hierárquicos superiores e de fatores externos, busca-se, à luz da Teoria da Agência, investigar se o principal também percepciona o mesmo senso de justiça em relação ao princípio da controlabilidade. Beuren et al. (2015) citam que do ponto de vista dos gestores, o desejo da aplicação do princípio da controlabilidade decorre da busca de um senso de justiça e satisfação, porém, alguns aspectos controversos são encontrados, principalmente sob a ótica da Teoria da Agência, que supõe que todos os indivíduos agem em interesse próprio.

Um dos motivos citados por Giraud et al. (2008) é que o principal tem interesse em usar toda e qualquer informação à sua disposição para avaliar os esforços do agente, o que nem sempre ocorre devido à assimetria informacional. Outro argumento destaca as dificuldades inerentes à aplicação do princípio da controlabilidade, pois fatores incontroláveis nem sempre são fáceis de avaliar, a exemplo do impacto de uma crise econômica. Segundo Giraud et al. (2008), estudos empíricos mostram que poucas empresas aplicam plenamente o princípio da controlabilidade.

Além disso, sob a ótica do principal, eventos incontroláveis podem constituir elementos contingentes, que fazem parte do processo de gestão. Portanto, caberia o entendimento de que esses elementos também deveriam ser gerenciados pelos gestores no decorrer do desenvolvimento das suas atribuições. Sob a ótica do principal, a aplicação do princípio da controlabilidade poderia acarretar o pagamento de recompensas ao agente com risco de descapitalização da organização. Pode-se exemplificar o contexto em que, por fatores incontroláveis ao agente, a organização não obteve resultados positivos durante o período. Eliminando o efeito desses fatores, o agente não seria penalizado no momento da avaliação de seu desempenho, obtendo a sua recompensa, mesmo em um momento que a empresa não apresenta resultados favoráveis.

Com base nesta explanação, e embasado no estudo de Giraud et al. (2008), referente ao baixo número de empresas que aplicam plenamente o princípio da controlabilidade, muitas vezes por ser o mesmo conflitante com outros princípios como a congruência (coerência com os objetivos globais da empresa) e a simplicidade na avaliação dos gestores, bem como nos resultados apresentados que sugerem que nem sempre os gestores tem interesse em ter neutralizadas as interferências em sua avaliação de desempenho, evidencia-se a seguinte hipótese: 
$\mathbf{H}_{2}$ : Na concepção do principal (representado por alunos de pós-graduação especialização), a aplicação do princípio da controlabilidade diminui a percepção de justiça distributiva em relação ao Sistema de Controle Gerencial.

\section{Método}

A pesquisa caracteriza-se como um estudo de natureza explicativa, com abordagem quantitativa, e experimental. A natureza explicativa decorre do propósito de "identificar fatores que determinam ou contribuem para a ocorrência de fenômenos" (Gil, 2017, p. 126), no caso fatores que possam explicar a variação na percepção de justiça. Nesses casos a abordagem experimental é a mais recomendada (Gil, 2017; Richardson, 2017).

Quanto ao delineamento experimental, segundo Gil (2017), consiste em determinar um objeto de estudo, selecionar as variáveis capazes de influenciá-lo e definir as formas de controle e de observação dos efeitos que a variável produz no objeto. Trata-se, portanto, de uma pesquisa em que o pesquisador é um agente ativo, e não um observador passivo. Gil (2017) cita ainda que, na pesquisa experimental, as hipóteses referem-se, geralmente, ao estabelecimento de relações causais entre variáveis.

A experimentação é "um processo de observação feita em uma situação planejada de tal forma a atender à finalidade proposta" (Martins \& Theóphilo, 2016, p. 54). As modalidades de pesquisa experimental incluem o pré-experimento, o experimento autêntico e o quase-experimento (Martins \& Theóphilo, 2016). Para esta pesquisa, optou-se pela modalidade pré-experimento, que caracteriza-se pela ausência de aleatoriedade na escolha dos sujeitos que irão compor os grupos, bem como controle mínimo (Martins \& Theóphilo, 2016). Também, segundo Gil (2017), na modalidade pré-experimento, os sujeitos são submetidos a um estímulo (no caso a aplicação ou não do princípio da controlabilidade) e, posteriormente, estudam-se os resultados (percepção de justiça dos sujeitos). Nessas situações não há controle de outras variáveis, e o pré-experimento não tem validade interna nem externa (Gil, 2017).

A variável dependente para esta pesquisa foi a percepção de justiça enquanto que a variável independente foi a aplicação do princípio da controlabilidade. Portanto, a aplicação do princípio da controlabilidade deve constituir-se como causa que estabelece um efeito na variável percepção de justiça. 
Para a coleta dos dados os respondentes foram divididos em dois grupos, sendo um representativo da parte do agente e o outro representando a parte do principal. Para representar o agente foi escolhido um grupo de alunos prestes a formarem-se no curso superior de Administração. A escolha de alunos com esse perfil partiu da premissa de que muitos já exercem função de gestor ou estão prestes a exercê-la, sendo que já estão participando de processo de avaliação de desempenho ou muito provavelmente participarão.

O segundo grupo, que representa o principal, foi escolhido entre alunos que já estão formados na graduação e atualmente estão frequentando cursos de especialização. A escolha desta população partiu do pressuposto de que muitos destes alunos são empresários ou tem perfil empreendedor, escolhidos para representar o principal, bem como já estão familiarizados com os conceitos de avaliação de desempenho.

A coleta de dados foi realizada pela aplicação de questionário. No momento da aplicação do questionário, bem como no cabeçalho do mesmo era solicitado aos sujeitos participantes que se colocassem na posição de gestores/funcionários (representando o agente) ou então na posição de proprietários/acionistas (representando o principal). Foram explanadas as condições de anonimato e voluntariado. Os dados foram coletados entre os dias 04 e 22 de novembro de 2016. As questões dos questionários foram adaptadas dos estudos de Giraud et al. (2008), Angonese e Beuren (2014), Beuren et al. (2016). Após esse período, os dados coletados foram tabulados em planilha eletrônica e, em seguida, submetidos a tratamento estatístico descritivo, análise de frequência e análise de correlação de Spearman.

A população da pesquisa compreendeu 83 alunos dos cursos de pós-graduação nível especialização, em ciências contábeis, administração e economia e 64 alunos formandos do curso de administração. Desse total, 68 alunos de cursos de especialização e 40 alunos formandos em administração responderam ao questionário de pesquisa. Foram excluídos 18 questionários referentes aos alunos de especialização por apresentarem todas as respostas com a mesma opção. A amostra totalizou 50 respondentes representando o principal e 40 respondentes representando o agente. A amostra caracterizou-se como não probabilística e intencional, consistindo em um limitador da pesquisa.

Os instrumentos de pesquisa aplicados aos alunos formandos em administração e aos alunos de especialização, respectivamente, estão explanados nas Tabelas 1 e 2 . 
Tabela 1 - Questionário aplicado ao Agente em novembro

1. Imagine que você é gestor em uma empresa. Parte da tua remuneração está atrelada a um sistema de avaliação de desempenho. Imagine também que, decisões de gestores de mesmo nível hierárquico ou de nível hierárquico superior, bem como fatores externos a empresa como catástrofes, crises, greves, podem afetar o desempenho da empresa e, consequentemente, o teu desempenho, refletindo na tua remuneração. Considerando este contexto, marque as seguintes questões indicando, numa escala de 1 a 5 , o teu grau de concordância:

1.1 No momento da avaliação do teu desempenho, as interferências geradas por decisões tomadas por gerentes de mesmo nível hierárquico devem ser neutralizadas?

\begin{tabular}{|l|l|l|l|l|l|l|} 
Discordo Totalmente & 1 & 2 & 3 & 4 & 5 & Concordo Totalmente \\
\hline
\end{tabular}

1.2 No momento da avaliação do teu desempenho, as interferências geradas por decisões tomadas por superiores hierárquicos devem ser neutralizadas?

\begin{tabular}{|l|l|l|l|l|l|l|} 
Discordo Totalmente & 1 & 2 & 3 & 4 & 5 & Concordo Totalmente \\
\hline
\end{tabular}

1.3 No momento da avaliação do teu desempenho, as interferências de fatores externos, como catástrofes, crises, etc. devem ser neutralizadas?

\begin{tabular}{|c|c|c|c|c|c|c|}
\hline Discordo Totalmente & 1 & 2 & 3 & 4 & 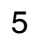 & Concordo Totalmente \\
\hline \multicolumn{7}{|c|}{$\begin{array}{l}\text { 2. Eliminando as interferências decorrentes de decisões tomadas por gerentes ou superiores hie- } \\
\text { rárquicos, bem como aquelas interferências decorrentes de fatores externos (catástrofes, crises, } \\
\text { etc.), entendo que minha avaliação de desempenho e a parcela da remuneração dela decorrente } \\
\text { pode ser considerada justa. }\end{array}$} \\
\hline Discordo Totalmente & 1 & 2 & 0 & 4 & 5 & Concordo Totalmente \\
\hline
\end{tabular}

Fonte: adaptados dos estudos de Giraud et al. (2008), Angonese e Beuren (2014), Beuren et al (2016).

Observam-se nas Tabelas 1 e 2 que, para cada construto, foram formuladas assertivas, em relação às quais foi solicitado aos respondentes que indicassem o seu grau de concordância em uma escala de cinco pontos, sendo: $1=$ discordo totalmente; 2 = discordo parcialmente; 3 = não concordo nem discordo; 4 = concordo parcialmente; 5 = concordo totalmente. Optou-se pela escala Likert de cinco pontos uma vez que as escalas de cinco e sete pontos são muito semelhantes em termos de resultados médios, como destacaram (Vieira \& Dalmoro, 2008). Os autores ainda sugerem que escalas com maiores números de itens geralmente são mais indicadas quando os entrevistados dominam o assunto objeto de estudo ou quando este tem muitos atributos. 
Tabela 2 - Questionário aplicado ao Principal em novembro

1. Imagine que você é proprietário de uma empresa. Parte da remuneração dos teus funcionários está atrelada a um sistema de avaliação de desempenho. Imagine também que, decisões de gestores de mesmo nível hierárquico ou de nível hierárquico superior, bem como fatores externos a empresa como catástrofes, crises, greves, podem afetar o desempenho da empresa e, consequentemente, o desempenho dos teus funcionários, refletindo na remuneração deles. Considerando este contexto, responda as seguintes questões indicando, numa escala de 1 a 5 , o grau de concordância:

1.1 No momento da avaliação do desempenho dos teus funcionários, as interferências gerada por decisões tomadas por gerentes de mesmo nível hierárquico devem ser neutralizadas?

\begin{tabular}{|l|l|l|l|l|l|l|}
\hline Discordo Totalmente & 1 & 2 & 3 & 4 & 5 & Concordo Totalmente \\
\hline
\end{tabular}

1.2 No momento da avaliação do desempenho dos teus funcionários, as interferências geradas por decisões tomadas por superiores hierárquicos devem ser neutralizadas?

\begin{tabular}{|l|l|l|l|l|l|l|} 
Discordo Totalmente & 1 & 2 & 3 & 4 & 5 & Concordo Totalmente \\
\hline
\end{tabular}

1.3 No momento da avaliação do desempenho dos teus funcionários, as interferências de fatores externos, como catástrofes, crises, etc. devem ser neutralizadas?

\begin{tabular}{|c|c|c|c|c|c|c|}
\hline Discordo Totalmente & 1 & 2 & 3 & 4 & 5 & Concordo Totalmente \\
\hline \multicolumn{7}{|c|}{$\begin{array}{l}\text { 2. Eliminando as interferências decorrentes de decisões tomadas por gerentes ou superiores hie- } \\
\text { rárquicos, bem como aquelas interferências decorrentes de fatores externos (catástrofes, crises, } \\
\text { etc.), entendo que a avaliação de desempenho dos meus funcionários, bem como a parcela da } \\
\text { remuneração dela decorrente, e paga aos mesmos, pode ser considerada justa. }\end{array}$} \\
\hline
\end{tabular}

\begin{tabular}{|c|c|c|c|c|c|c|}
\hline Discordo Totalmente & 1 & 2 & 3 & 4 & 5 & Concordo Totalmente \\
\hline
\end{tabular}

Na próxima seção são apresentadas a descrição e análise dos resultados. A análise é apresentada por grupo estudado, agente e principal.

\section{Descrição e análise dos resultados}

A Tabela 3 apresenta a estatística descritiva das variáveis analisadas para o agente. Observa-se que a média mais relevante da amostra encontra-se na variável dependente Justiça Distributiva, demonstrando a importância deste tema para os gestores. 
Tabela 3 - Estatística descritiva das variáveis para o Agente

\begin{tabular}{l|c|c|c|c|c|c}
\hline \multicolumn{1}{c|}{ Variável } & Média & Mediana & Desvio padrão & Menor & Maior & Amplitude \\
\hline Justiça Distributiva & 3,9 & 4 & 0,810191 & 2 & 5 & 3 \\
Mesmo Nível & 3,175 & 3 & 0,843907 & 2 & 5 & 3 \\
Superior Hierárquico & 3,25 & 3 & 1,21423 & 1 & 5 & 4 \\
Fatores Externos & 3,175 & 3 & 1,17424 & 1 & 5 & 4 \\
\hline
\end{tabular}

Fonte: dados primários (2016).

No desvio padrão, a maior dispersão em relação à média encontra-se na variável desejo de neutralização de decisões tomadas por superior hierárquico. Nota-se também que nenhum dos respondentes discordou totalmente da eliminação de fatores incontroláveis como elementos que potencializam a percepção de justiça distributiva. A mediana confirma que a maioria dos agentes percepciona como justa a aplicação do princípio da controlabilidade na sua avaliação de desempenho.

A Tabela 4 apresenta a estatística descritiva das variáveis analisadas para o principal. Observa-se que a média mais relevante da amostra também está na variável dependente Justiça Distributiva, embora o desejo de neutralização de decisões tomadas por gestores de mesmo nível hierárquico apresente aproximadamente o mesmo resultado.

Tabela 4 - Estatística descritiva das variáveis para o Principal

\begin{tabular}{l|c|c|c|c|c|c}
\hline \multicolumn{1}{c|}{ Variável } & Média & Mediana & Desvio padrão & Menor & Maior & Amplitude \\
\hline Justiça Distributiva & 3,68 & 4 & 1,09619 & 1 & 5 & 4 \\
Mesmo Nível & 3,66 & 4 & 1,11776 & 1 & 5 & 4 \\
Superior Hierárquico & 2,98 & 3 & 1,42127 & 1 & 5 & 4 \\
Fatores Externos & 3,04 & 3 & 1,4563 & 1 & 5 & 4 \\
\hline
\end{tabular}

Fonte: dados primários (2016).

No desvio padrão, a variável que apresentou maior dispersão em relação à média foi a variável que expressa o desejo de neutralização de fatores externos. Diferente do que ocorreu com as respostas dos agentes, nos dados fornecidos pelo principal, todas as questões apresentaram respostas dentro de um parâmetro de amplitude máximo. Nos resultados do principal, novamente percebe-se que a mediana confirma que a maioria dos respondentes percepciona como justa a aplicação do princípio da controlabilidade na avaliação de desempenho dos seus 
subordinados. Os dados revelam que, tanto o agente quanto o principal tem interesse no tema justiça distributiva.

Analisadas as estatísticas descritivas, na sequência são apresentadas as tabelas com a análise de frequência que mostram a percepção do agente e do principal em relação à justiça e o desejo de neutralização de fatores incontroláveis (princípio da controlabilidade).

Tabela 5 - Percepção do Agente em relação à neutralização dos fatores incontroláveis na sua avaliação de desempenho

\begin{tabular}{l|c|c|c}
\hline $\begin{array}{c}\text { Neutralização do fator incontrolável } \\
\text { Concordância }\end{array}$ & $\begin{array}{c}\text { Gerentes de mesmo } \\
\text { nível hierárquico }\end{array}$ & $\begin{array}{c}\text { Superiores } \\
\text { Hierárquicos }\end{array}$ & $\begin{array}{c}\text { Fatores } \\
\text { Externos }\end{array}$ \\
\hline 1 - Discordo totalmente & $0 \%$ & $10 \%$ & $12 \%$ \\
2 - Discordo parcialmente & $20 \%$ & $17 \%$ & $10 \%$ \\
3 - Não concordo nem discordo & $50 \%$ & $25 \%$ & $38 \%$ \\
4 - Concordo parcialmente & $23 \%$ & $33 \%$ & $28 \%$ \\
5 - Concordo totalmente & $7 \%$ & $15 \%$ & $12 \%$ \\
Total de respondentes & 40 & 40 & 40 \\
\hline
\end{tabular}

Fonte: dados primários (2016)

Pela análise dos dados da Tabela 5, percebe-se que a maioria dos respondentes concorda parcialmente com a neutralização das interferências geradas pelos superiores hierárquicos, sendo que no acumulado o percentual de concordância atinge 48\%. Na sequência, o maior percentual de desejo de neutralização é para os fatores externos com $40 \%$, seguido pelo desejo de neutralização de decisões tomadas por gestores de mesmo nível hierárquico com $30 \%$.

Os resultados divergem dos estudos de Angonese e Beuren (2014), em que, para a amostra estudada, prevalece o desejo de neutralização para o fator incontrolável relativo a eventos externos à organização. No entanto, assemelham-se aos resultados de Giraud et al. (2008) que constataram uma maior preocupação dos gestores em neutralizar fatores incontroláveis relacionados às decisões de gerentes de mesmo nível hierárquico ou de decisões de superiores hierárquicos, não encontrando significância estatística para o desejo de neutralização dos fatores externos. Giraud et al. (2008) atribuíram este resultado à percepção dos gestores de que eles, em suas atividades, deveriam atuar como empreendedores, suportando e gerenciando os riscos decorrentes dos fatores externos. 
Merchant (1989) em sua pesquisa revelou que existem diferenças na aplicação do princípio da controlabilidade. Testou diversos tipos de fatores incontroláveis, e constatou que as organizações procedem ajustem com mais frequência em fatores internos do que fatores externos.

Para perceber se havia relação entre a variável justiça distributiva e o princípio da controlabilidade, materializado pelo desejo de neutralização das três categorias de fatores incontroláveis, foi realizada uma análise de correlação de Spearman cujos resultados constam na Tabela 6 .

Tabela 6 - Coeficiente de correlação de Spearman com base nos dados do Agente

\begin{tabular}{l|c|c|c|c|c}
\hline \multicolumn{1}{c|}{ Variável 1 } & Variável 2 & Casos & Coef. correl. & Estatística t & Valor-p $^{\text {a }}$ \\
\hline Gestores Mesmo Nível & Justiça Distributiva & 40 & $+0,2918$ & 1,8809 & 0,0677 \\
Superiores Hierárquicos & Justiça Distributiva & 40 & $+0,1154$ & 0,7161 & 0,4783 \\
Fatores Externos & Justiça Distributiva & 40 & $+0,0983$ & 0,6090 & 0,5462 \\
\hline
\end{tabular}

a. teste bilateral da nulidade do coeficiente de correlação.

Fonte: dados primários (2016)

Analisando os dados que constam na Tabela 6, percebe-se que a percepção de justiça distributiva está positivamente correlacionada com o desejo de neutralização de decisões tomadas por gestores de mesmo nível hierárquico. Significa que quanto maior o desejo de neutralização de decisões tomadas por gestores do mesmo nível hierárquico maior tende a ser a percepção de justiça distributiva. Percebe-se também na Tabela 6 que o desejo de neutralização de decisões tomadas por superiores hierárquicos e o desejo de neutralização de influências de fatores externos incontroláveis na avaliação de desempenho apresentam correlação fraca com a percepção de justiça distributiva, bem como não apresentam significância estatística.

A hipótese 1 mencionava que na concepção do agente (representado pelos alunos concluintes do curso de administração), a aplicação do princípio da controlabilidade aumenta a percepção de justiça distributiva em relação ao sistema de controle gerencial. Os resultados apontam para uma confirmação parcial da hipótese 1. A percepção de justiça aumenta apenas em relação ao desejo de neutralização de decisões tomadas por gestores de mesmo nível hierárquico.

Os resultados dos dados coletados junto à amostra que representou o principal são apresentados na Tabela 7, evidenciando o desejo do principal em relação à neutralização dos fatores incontroláveis na avaliação de desempenho dos seus subordinados. 
Tabela 7 - Percepção do Principal em relação à neutralização dos fatores incontroláveis na avaliação de desempenho dos gestores

\begin{tabular}{l|c|c|c}
\hline $\begin{array}{c}\text { Neutralização do fator incontrolável } \\
\text { Concordância }\end{array}$ & $\begin{array}{c}\text { Gerentes de mesmo } \\
\text { nível hierárquico }\end{array}$ & $\begin{array}{c}\text { Superiores } \\
\text { hierárquicos }\end{array}$ & $\begin{array}{c}\text { Fatores } \\
\text { externos }\end{array}$ \\
\hline 1 - Discordo totalmente & $2 \%$ & $18 \%$ & $20 \%$ \\
2 - Discordo parcialmente & $16 \%$ & $30 \%$ & $22 \%$ \\
3 - Não concordo nem discordo & $30 \%$ & $4 \%$ & $12 \%$ \\
4 - Concordo parcialmente & $24 \%$ & $32 \%$ & $26 \%$ \\
5 - Concordo totalmente & $28 \%$ & $16 \%$ & $20 \%$ \\
Total de respondentes & 50 & 50 & 50 \\
\hline
\end{tabular}

Fonte: dados primários (2016).

Através da análise dos dados da Tabela 7, percebe-se que $28 \%$ dos respondentes concorda totalmente com a neutralização das interferências dos gerentes de mesmo nível hierárquico, sendo que no acumulado de concordância este percentual atinge $52 \%$, ou seja, mais da metade dos respondentes. Assim, este passa a representar o fator com maior percentual de interesse em neutralização na percepção do principal. Na sequência, $32 \%$ dos respondentes concordam parcialmente com a neutralização das interferências geradas pelos superiores hierárquicos, sendo que no acumulado o percentual de concordância atinge $48 \%$, igualando-se aos resultados do agente. Porém, ao analisarmos o percentual acumulado de discordância, obtêm-se o mesmo resultado, revelando uma divisão de opiniões. $\mathrm{O}$ mesmo ocorre em relação aos fatores externos, que apresentam percentuais aproximados entre concordância e discordância.

Os achados contrariam alguns estudos, principalmente sob a ótica da Teoria da Agência, conforme citam Antle e Demski (1988), Anthony e Govindarajan (2008) que sob certas condições, a exemplo da assimetria de informação, é do interesse do principal usar toda e qualquer informação a sua disposição para avaliar os esforços do agente, incluindo indicadores além do controle do agente. Giraud et al. (2008) citam em seus estudos que nem sempre é do interesse de uma empresa aplicar o princípio da controlabilidade, referindo-se a Merchant (1989), que exemplifica este desinteresse tendo em vista o fato de que, responsabilizar os gerentes por fatores de desempenho que eles não podem controlar totalmente, mas que podem influenciar, aconselhando-os a continuar prestando atenção a estes fatores influenciáveis.

Para verificar se havia relação entre a variável justiça distributiva e o princípio da controlabilidade, consubstanciado pelo desejo de neutralização dos três 
fatores incontroláveis por parte do principal, foi realizada a análise de correlação de Spearman cujos resultados constam na Tabela 8.

Tabela 8 - Coeficiente de correlação de Spearman com base nos dados do Principal

\begin{tabular}{l|c|c|c|c|c}
\hline \multicolumn{1}{c|}{ Variável 1 } & Variável 2 & Casos & Coef. correl. & Estatística t & Valor-p $^{\text {a }}$ \\
\hline Gestores Mesmo Nível & Justiça Distributiva & 50 & $+0,2539$ & 1,8187 & 0,0752 \\
Superiores Hierárquicos & Justiça Distributiva & 50 & $+0,1677$ & 1,1788 & 0,2443 \\
Fatores Externos & Justiça Distributiva & 50 & $+0,3205$ & 2,3438 & 0,0233 \\
\hline
\end{tabular}

a. teste bilateral da nulidade do coeficiente de correlação.

Fonte: dados primários (2016)

Analisando os dados da Tabela 8, constata-se que a percepção de justiça distributiva está positivamente correlacionada com o desejo de neutralização de fatores externos e com decisões tomadas por gestores de mesmo nível hierárquico. Significa que quanto maior o desejo de neutralização de fatores externos e de decisões tomadas por gestores do mesmo nível hierárquico, maior tende a ser a percepção de justiça distributiva. Percebe-se também na Tabela 8 que o desejo de neutralização de decisões tomadas por superiores hierárquicos apresenta correlação fraca com a percepção de justiça distributiva, bem como não apresenta significância estatística.

A hipótese 2 referia que na concepção do principal (representado pelos alunos de pós-graduação), a aplicação do princípio da controlabilidade diminui a percepção de justiça distributiva em relação ao sistema de controle gerencial. Os resultados indicam que esta hipótese não foi confirmada. A percepção de justiça aumenta em relação ao desejo de neutralização de fatores incontroláveis na hora de avaliar o desempenho dos funcionários.

Os dados comparativos sobre a percepção de justiça por parte do agente e do principal encontram-se demonstrados na Tabela 9 .

Tabela 9 - Percepção de justiça sobre a aplicação do princípio da controlabilidade

\begin{tabular}{l|c|c}
\multicolumn{1}{c|}{ Concordância } & Agente & Principal \\
\hline 1 - Discordo totalmente & & $6 \%$ \\
2 - Discordo parcialmente & $2 \%$ & $10 \%$ \\
3 - Não concordo nem discordo & $30 \%$ & $14 \%$ \\
4 - Concordo parcialmente & $43 \%$ & $50 \%$ \\
5 - Concordo totalmente & $25 \%$ & $20 \%$ \\
Total de respondentes & 40 & 50 \\
\hline
\end{tabular}

Fonte: dados primários (2016). 
Pela análise da Tabela 9, os números mostram que, tanto o agente quanto o principal percepcionam como justa a neutralização dos fatores incontroláveis quando da avaliação de desempenho. Apenas $16 \%$ dos representantes do principal discordam. Estes resultados seguem a linha de estudos de Giraud et al. (2008), Langevin e Mendoza (2013), Beuren et al. (2016) entre outros, que mencionam como principal argumento apresentado na literatura para a aplicação do princípio da controlabilidade o de que, quando responsabilizados por acontecimentos que não controlam, os gerentes percebem a avaliação como desleal e tornam-se insatisfeitos, desmotivados, o que pode resultar em comportamento prejudicial à empresa.

\section{Considerações finais}

A justiça nas organizações é uma temática complexa, pois envolve um conjunto de fatores internos e externos ligados ao processo de avaliação de desempenho e às regras de distribuição de benefícios entre os empregados. Pressupõe-se que a aplicação do princípio da controlabilidade pode estabelecer um senso de justiça na avaliação de desempenho dos gestores, especialmente da justiça distributiva, que diz respeito a como uma organização distribui os recursos financeiros disponíveis entre seus empregados.

Este estudo objetivou verificar a percepção de justiça que o principal e o agente apresentam em relação ao princípio da controlabilidade. Para tanto foram elaboradas duas hipóteses, baseadas nos estudos de Giraud et al. (2008), Angonese e Beuren (2014), Beuren et al. (2016).

A hipótese um (H1) buscou investigar se, na concepção do agente (alunos concluintes do curso de administração), a aplicação do princípio da controlabilidade aumenta a percepção de justiça distributiva em relação ao Sistema de Controle Gerencial. Esta hipótese foi parcialmente confirmada, pois pelo teste de correlação de Spearman, verifica-se que há correlação positiva apenas entre a variável dependente justiça distributiva e a variável independente desejo de neutralização de decisões de gestores de mesmo nível hierárquico. Para esta amostra não houve a preocupação em neutralizar as interferências dos superiores hierárquicos e nem dos fatores externos. Este resultado assemelha-se aos resultados encontrados nos estudos de Giraud et al. (2008) que realizaram uma pesquisa com 265 gerentes franceses e coletaram dados quantitativos e qualitativos. Os resultados mostraram que os gerentes não desejam uma aplicação total do princípio de controlabilidade,

Teoria e Evidência Econômica - a. 27, n. 56, p. 33-53, jan./jun. 2021 
adotando uma posição diferente dependendo do tipo de fator incontrolável: eles desejam que o princípio de controlabilidade seja aplicado quando seu desempenho é afetado por fatores internos a exemplo de decisões tomadas por outros gerentes da empresa ou por seus superiores, mas não quando seus resultados são afetados por eventos externos.

A hipótese dois (H2) investigou se, na concepção do principal (alunos de especialização), a aplicação do princípio da controlabilidade diminui a percepção de justiça distributiva em relação ao Sistema de Controle Gerencial. Esta hipótese foi rejeitada, pois há correlação positiva entre a variável dependente justiça distributiva e as variáveis independentes: desejo de neutralização de decisões de gestores de mesmo nível hierárquico e neutralização de fatores externos, demonstrando que o principal não tem diminuída sua percepção de justiça distributiva pela aplicação do princípio da controlabilidade nestes dois quesitos. Os resultados mostram que ambos os grupos percepcionam como justa a aplicação do princípio da controlabilidade.

Salienta-se que, como a pesquisa teve um caráter pré-experimental, ocorrido pela definição dos respondentes, sem que, necessariamente, os mesmos exerçam cargos de gestores ou atuem como proprietários/acionistas de empresas, este caráter pode interferir nos resultados. Outra limitação a considerar, também decorrente do modelo pré-experimental, é a de que o grau de conhecimento dos respondentes sobre o tema (controlabilidade e justiça organizacional), antes de responderem ao questionário, não foi averiguado. Entende-se que conhecimento prévio sobre a temática pode influenciar os resultados.

Recomenda-se a realização de novos estudos, com públicos distintos, preferencialmente com vivência tanto em gestão de empresas para representar o agente, como com reais proprietários/acionistas de empresas para representar o principal. Pesquisas de cunho qualitativo podem contribuir com este campo de pesquisa. 


\title{
Perception of Justice by the Principal and the Agent in Relation to the Principle of Controllability
}

\begin{abstract}
This study aims to verify if the application of the controllability principle influences the perception of justice, both, by the principal and by the agent. The research has a descriptive nature, with a quantitative approach. It is experimental by the research procedure. Data collection was performed through the application of a questionnaire to 40 graduating students of management course, representing the agent and 50 postgraduate students representing the principal. The collected data were tabulated in spreadsheet and subjected to descriptive statistical treatment, frequency analysis and Spearman correlation analysis. The results show that the neutralization of the interference of managers of the same hierarchical level increases the perception of distributive justice by the agent. In the conception of the principal, there is a positive correlation between distributive justice and the desire to neutralize decisions made by managers of the same hierarchical level and external factors, demonstrating that the principal has not diminished their perception of distributive justice by applying the principle of controllability in these two items, contradicting the initial idea that involved the assumptions of the Agency Theory.
\end{abstract}

Keywords: Organizational Justice. Theory of the Agency. Management control. Performance evaluation.

\section{Percepción de Justicia por parte del Principal y del Agente en relación al Principio de la Controlabilidad}

\section{Resumen}

Este estudio tiene por objeto verificar si la aplicación del principio de la controlabilidad influye en la percepción de la justicia, tanto por parte del principal y por parte del agente. La investigación presenta naturaleza descriptiva, con abordaje cuantitativo. Es de carácter experimental por el procedimiento de la investigación. La recolección de datos fue realizada por medio de la aplicación de cuestionario para 40 alumnos concluyentes del curso superior de administración, representando al agente y 50 alumnos de postgrado representando el principal. Los datos recolectados fueron tabulados en hoja de cálculo y sometidos a tratamiento estadístico descriptivo, análisis de frecuencia y análisis de correlación de Spearman. Los resultados muestran que la neutralización de la interferencia de gestores del mismo nivel jerárquico aumenta la percepción de la justicia distributiva por parte del agente. En la concepción del principal, hay correlación positiva entre la justicia distributiva y el deseo de neutralización de decisiones tomadas por gestores del mismo nivel jerárquico y factores externos, demostrando que el principal no ha disminuido su percepción de justicia distributiva por la aplicación del principio de la controlabilidad en estos dos en contra de la idea inicial que implicaba los presupuestos de la Teoría de la Agencia.

Palabras clave: Justicia Organizacional. Teoría de la Agencia. Control de gestión. Evaluación del desempeño.

Teoria e Evidência Econômica - a. 27, n. 56, p. 33-53, jan./jun. 2021 


\section{Referências}

Aguiar, A. B. de, Teixeira, A. J. C., Nossa, V., \& Gonzaga, R. P. (2012). Associação entre Sistema de Incentivos Gerenciais e Práticas de Contabilidade Gerencial. Revista de Administração de Empresas, 52(1), pp. 040-054. Recuperado de http://www.producao.usp.br/bitstream/handle/ BDPI/38235/S0034-75902012000100004.pdf?sequence=1

Angonese, R., \& Beuren, I. M. (2014). Percepção de alunos de cursos de pós-graduação sobre a aplicação do princípio da controlabilidade. Pensar Contábil, 16(59), 39-48. Recuperado de http:// www.spell.org.br/documentos/ver/31236/percepcao-de-alunos-de-cursos-de-pos-graduacao-sobre-a-aplicacao-do-principio-da-controlabilidade

Anthony, R. N., \& Govindarajan, V. (2008). Sistemas de Controle Gerencial. (12a ed.). Porto Alegre: AMGH.

Antle, R., \& Demski, J. S. (1988). The controllability principle in responsibility accounting. Accounting Review, 63(1), pp.700-718. Recuperado de https://fisher.osu.edu/ young.53/Antle_Demski.pdf.

Assmar, E. M. L., Ferreira, M. C., \& SOUTO, S. O. (2005). Justiça organizacional: uma revisão crítica da literatura. Psicologia: Reflexão e Crítica, 18(3), pp. 443-453. Recuperado de http:// www.redalyc.org/pdf/188/18818319.pdf

Beugré, C. D., \& Baron, R. A. (2001). Perceptions of Systemic Justice: The Effects of Distributive, Procedural, and Interactional Justice. Journal of Applied Social Psychology, 31, 2, p. 324-339. Recuperado de http://onlinelibrary.wiley.com/doi/10.1111/j.1559-1816.2001. tb00199.x/epdf?r3_referer=wol\&tracking_action=preview_click\&show_checkout=1\&purchase referrer=onlinelibrary.wiley.com\&purchase_site_license=LICENSE_DENIED

Beuren, I. M., Amaro, H. D., \& Silva, P. Y. (2015). Percepção dos Gestores em Relação ao Princípio da Controlabilidade para o Alcance da Justiça Organizacional. Revista Eletrônica de Administração, 81(2), 378-405. Recuperado de http:/www.scielo.br/pdf/read/v21n2/1413-2311read-21-02-00378.pdf

Beuren, I. M., Klein, L., Lara, F. L., \& Almeida, L. B. (2016). Percepção de Justiça nos Sistemas de Controle Gerencial Aumenta Comprometimento e Confiança dos Gestores? Revista de Administração Contemporânea. 20(5), 216-237. Recuperado de http://www.scielo.br/pdf/rac/v20n2/ 1982-7849-rac-20-2-0216.pdf. doi:/10.1590/1982-7849rac2016140083

Burkert, M., Fischer, F. M., \& Schaffer, U. (2011). Application of the controllability principle and managerial performance: the role of role perceptions. Management Accounting Research, 22(3), 143-159. Recuperado de https://www.researchgate.net/publication/228271618_Application_of_ the_Controllability_Principle_and_Managerial_Performance_The_Role_of_Role_Perceptions

Folger, R. G., \& Cropanzano, R. (1998) Organizational justice and human resource management. London: Sage.

Gil, A. C. (2017). Como elaborar projetos de pesquisa. (6a ed.). São Paulo: Atlas.

Giraud, F., Langevin, P., \& Mendoza, C. (2008). Justice as a rationale for the controllability principle: a study of managers' opinions. Management Accounting Research, 19(1), pp.32-44. Recuperado de http://www.academia.edu/8259814/Justice_as_a_rationale_for_the_controllability_ principle_A_study_of_managers_opinions 
Langevin, P., \& Mendoza, C. (2013). How can management control system fairness reduce managers' unethical behaviours? European Management Journal, 31(3), p.209-222. Recuperado de https://pdfs.semanticscholar.org/1828/ae58dad69a7c95fabd7df3e3290e2e3cf689.pdf

Martins, G. A., \& Theóphilo, C. R. (2016). Metodologia da investigação científica para ciências sociais aplicadas. São Paulo: Atlas.

Merchant, K. (1989). Rewarding results: motivating profit center managers. Boston: Harvard Business School Press.

Merchant, K. A., \& Van der Stede, W. A. (2007). Management control systems: Performance measurement, evaluation and incentives. New York: Financial Times/Prentice Hall.

Richardson, R. J. (2017). Pesquisa social: métodos e técnicas. (4a ed.). São Paulo: Atlas.

Sotomayor, A. M. S. B. (2006). As percepções de justiça organizacional na avaliação de desempenho: Consequências sobre o compromisso organizacional e o compromisso face ao superior hierárquico. (Tese de doutorado). Instituto Superior de Economia e Gestão, Universidade Técnica de Lisboa, Portugal. Recuperado de http://www.repository.utl.pt/handle/10400.5/3662

Sotomayor, A. M. S. B. (2007). Avaliação de desempenho e compromisso organizacional: a perspectiva da justiça organizacional. Revista Universo Contábil, 3(3), 87-100. Recuperado de http:// www.spell.org.br/documentos/ver/26568/avaliacao-de-desempenho-e-compromisso-organizacional--a-perspectiva-da-justica-organizacional

Vieira, K. M., \& Dalmoro, M. (2008). Dilemas na Construção de Escalas Tipo Likert: o número de itens e a disposição influenciam nos resultados? Anais do Encontro Nacional da Associação Nacional de Pós-Graduação e Pesquisa em Administração, Rio de Janeiro, RJ, Brasil, 32. Recuperado de http://www.anpad.org.br/admin/pdf/EPQ-A1615.pdf 